\title{
Randomised controlled trial of high concentration versus titrated oxygen therapy in severe exacerbations of asthma
}

\author{
Kyle Perrin, ${ }^{1,2}$ Meme Wijesinghe, ${ }^{1,2}$ Bridget Healy, ${ }^{1,2}$ Kirsten Wadsworth, ${ }^{1}$ \\ Richard Bowditch, ${ }^{1,2}$ Susan Bibby, 1,2 Tanya Baker, ${ }^{1}$ Mark Weatherall, ${ }^{2,3}$ \\ Richard Beasley ${ }^{1,2,3}$
}

\begin{abstract}
See Editorial, p 931
- Additional tables are published online only. To view these files please visit the journal online (http://thorax.bmj. com).
\end{abstract}

${ }^{1}$ Medical Research Institute of New Zealand, Wellington, New Zealand

${ }^{2}$ Departments of Respiratory and Medicine and Emergency Medicine, Capital \& Coast District Health Board, Wellington, New Zealand ${ }^{3}$ Department of Medicine, University of Otago Wellington, Wellington, New Zealand

\section{Correspondence to}

Professor Richard Beasley, Medical Research Institute of New Zealand, Private Bag 7902, Wellington 6242, New Zealand; richard.beasley@mrinz.ac.nz

Received 8 November 2010 Accepted 24 March 2011

Published Online First

19 May 2011

\begin{abstract}
Background The effect on $\mathrm{PacO}_{2}$ of high concentration oxygen therapy when administered to patients with severe exacerbations of asthma is uncertain.

Methods 106 patients with severe exacerbations of asthma presenting to the Emergency Department were randomised to high concentration oxygen $(8 \mathrm{l} / \mathrm{min}$ via medium concentration mask) or titrated oxygen (to achieve oxygen saturations between 93\% and 95\%) for $60 \mathrm{~min}$. Patients with chronic obstructive pulmonary disease or disorders associated with hypercapnic respiratory failure were excluded. The transcutaneous partial pressure of carbon dioxide $\left(\mathrm{PtcO}_{2}\right)$ was measured at $0,20,40$ and $60 \mathrm{~min}$. The primary outcome variable was the proportion of patients with a rise in $\mathrm{Ptco}_{2}$ $\geq 4 \mathrm{~mm} \mathrm{Hg}$ at $60 \mathrm{~min}$.
\end{abstract}

Results The proportion of patients with a rise in $\mathrm{Ptco}_{2}$ $\geq 4 \mathrm{~mm} \mathrm{Hg}$ at 60 min was significantly higher in the high concentration oxygen group, 22/50 (44\%) vs 10/53 (19\%), RR 2.3 (95\% Cl 1.2 to 4.4, $\mathrm{p}<0.006)$. The high concentration group had a higher proportion of patients with a rise in $\mathrm{PtcO}_{2} \geq 8 \mathrm{~mm} \mathrm{Hg}, 11 / 50$ (22\%) vs $3 / 53$ $(6 \%)$, RR 3.9 (95\% Cl 1.2 to $13.1, p=0.016)$. All 10 patients with a final $\mathrm{Ptco}_{2} \geq 45 \mathrm{~mm} \mathrm{Hg}$ received high concentration oxygen therapy, and in five there was an increase in $\mathrm{PtcO}_{2} \geq 10 \mathrm{~mm} \mathrm{Hg}$.

Conclusion High concentration oxygen therapy causes a clinically significant increase in $\mathrm{PtcO}_{2}$ in patients presenting with severe exacerbations of asthma. A titrated oxygen regime is recommended in the treatment of severe asthma, in which oxygen is administered only to patients with hypoxaemia, in a dose that relieves hypoxaemia without causing hyperoxaemia.

Clinical trial number ACTRN12607000131459.

\section{INTRODUCTION}

It is well recognised that high concentration oxygen therapy may lead to carbon dioxide $\left(\mathrm{CO}_{2}\right)$ retention when administered to patients with acute exacerbations of chronic obstructive pulmonary disease (AECOPD) ${ }^{1}{ }^{2}$ and that worsening ventilation-perfusion mismatch due to release of hypoxic pulmonary vasoconstriction with a resulting increase in physiological dead space is one of the major mechanisms causing this effect. $^{3-7}$ In contrast, the risks and benefits of oxygen therapy in severe exacerbations of asthma are less well understood. As with AECOPD, the main gas exchange abnormality in severe exacerbations of asthma is ventilation-perfusion
Key messages

What is the key question?

- Does high concentration oxygen therapy cause an increase in $\mathrm{PacO}_{2}$ in severe exacerbations of asthma?

What is the bottom line?

- High concentration oxygen therapy causes a clinically significant increase in $\mathrm{PtcO}_{2}$ in patients presenting with severe exacerbations of asthma.

\section{Why read on?}

- In the treatment of severe asthma it is recommended that oxygen is administered only in patients with hypoxaemia, in a dose that relieves hypoxaemia without causing hyperoxaemia.

mismatch, ${ }^{8-10}$ and oxygen administration has been shown to worsen the degree of mismatch. ${ }^{10-15}$ There are preliminary data from case reports, case series and a single randomised controlled trial to suggest that high concentration oxygen therapy may potentially lead to $\mathrm{CO}_{2}$ retention in severe exacerbations of asthma. ${ }^{10-12}{ }^{16-21}$ However, there are no randomised controlled trials comparing high concentration oxygen therapy with a titrated oxygen regime, in which oxygen is administered only to patients with hypoxaemia, to relieve hypoxaemia but avoiding hyperoxaemia, as recommended in recent guidelines. ${ }^{22-24}$

In this randomised controlled trial we investigated the effects of high concentration oxygen therapy on $\mathrm{PaCO}_{2}$ in patients presenting to the Emergency Department (ED) with severe exacerbations of asthma. A comparison was made with oxygen therapy titrated as required to relieve hypoxaemia, with a target oxygen saturation of between $93 \%$ and $95 \%$. The current study was designed to test the hypothesis that uncontrolled high concentration oxygen would result in an increase in the $\mathrm{PaCO}_{2}$ compared with the titrated oxygen regime.

\section{METHODS \\ Subjects}

The study was conducted in the EDs of three metropolitan hospitals in Wellington, New 
Zealand: Wellington Hospital (tertiary public), Hutt Hospital (secondary public) and Kenepuru Hospital (secondary public). Patients presenting to the ED with asthma were approached by the investigator to assess potential eligibility. Patients aged between 18 and 65 years were eligible for inclusion if they met the following criteria: previous doctor diagnosis of asthma, history consistent with a current acute exacerbation of asthma and a forced expiratory volume in $1 \mathrm{~s}\left(\mathrm{FEV}_{1}\right) \leq 50 \%$ of predicted values at the time of first assessment. Patients with a diagnosis of COPD, or disorders associated with hypercapnic respiratory failure such as neuromuscular disease, chest wall restriction or obesity hypoventilation syndrome, were excluded from the study due to the potential for confounding. Patients who were unconscious, unable to speak or unable to perform spirometry were also excluded. Written informed consent was obtained from each patient.

\section{Study protocol}

Patients were randomly assigned to one of two oxygen regimes for $1 \mathrm{~h}$. Patients in the high concentration group received oxygen at a flow rate of $81 / \mathrm{min}$ via a medium concentration mask (Hudson RCI, Durham, North Carolina, USA) which delivers an $\mathrm{FiO}_{2}$ of between 0.4 and 0.78 . $^{25} 26$ Patients in the titrated group received oxygen only if their saturation was $\leq 92 \%$ on room air, with oxygen titrated as required at $5 \mathrm{~min}$ intervals, to achieve an oxygen saturation of $93-95 \%$ according to the protocol outlined in the online supplement Table S1. Flow rates up to $4 \mathrm{l} / \mathrm{min}$ were delivered via nasal cannulae (Hudson RCI) and those $>41 / \mathrm{min}$ were delivered by medium concentration mask.

A computerised randomisation sequence was generated by the biostatistician (MWe) and patients were enrolled and assigned to their treatment group by the clinical research fellows (MWi, KP, $\mathrm{BH}, \mathrm{KW}$ and $\mathrm{RBo}$ ). Allocation concealment was achieved by using a secure database which contained the randomisation sequence. Allocation was only revealed to the researchers when the patients were enrolled and their name entered in the database. Neither investigators nor patients could be blinded to the treatment regimes due to the requirement to titrate oxygen therapy in the control group.

A medical history was taken, each patient underwent a physical examination, and asthma therapy was administered in accordance with published guidelines. ${ }^{22} 23$ All patients received salbutamol $2.5 \mathrm{mg}$ and ipratropium bromide $0.5 \mathrm{mg}$ via an air-driven nebuliser (Portaneb, Respironics, Murrysville, Pennsylvania, USA) on arrival. Patients with severe asthma $\left(\mathrm{FEV}_{1} \quad 30-50 \%\right.$ predicted) received salbutamol $2.5 \mathrm{mg}$ via a nebuliser every $20 \mathrm{~min}$ and prednisone $40 \mathrm{mg}$ orally. Those with very severe asthma $\left(\mathrm{FEV}_{1}<30 \%\right.$ predicted) received salbutamol $2.5 \mathrm{mg}$ via a nebuliser every $15 \mathrm{~min}$, hydrocortisone $200 \mathrm{mg}$ intravenously and magnesium sulfate $2 \mathrm{~g}$ in $100 \mathrm{ml}$ of normal saline intravenously over $20 \mathrm{~min}$.

\section{Measures}

The transcutaneous partial pressure of carbon dioxide $\left(\mathrm{PtCO}_{2}\right)$ was used to estimate arterial $\mathrm{PaCO}_{2}$ using a combined oxygen saturation/ $/ \mathrm{PtCO}_{2}$ monitor (TOSCA, Radiometer, Basel, Switzerland). Transcutaneous $\mathrm{CO}_{2}$ monitors estimate $\mathrm{PaCO}_{2}$ by heating an earlobe probe to $42^{\circ} \mathrm{C}$ to enhance blood flow and 'arterialise' the underlying capillaries. $\mathrm{CO}_{2}$ diffuses through the skin and changes the $\mathrm{pH}$ of a thin layer of an electrolyte solution in the probe, and the resulting signal is converted to $\mathrm{PaCO}_{2}$. Measurements of $\mathrm{PtCO}_{2}, \mathrm{FEV}_{1}$, respiratory rate and heart rate were made at baseline $(0 \mathrm{~min})$ and at 20,40 and $60 \mathrm{~min}$. The oxygen saturation was measured continuously throughout the study period and recorded at 5 min intervals.

\section{Statistical analysis}

The prespecified primary outcome variable was the proportion of patients with a $\mathrm{PtCO}_{2}>38 \mathrm{~mm} \mathrm{Hg}$ and $\mathrm{FEV}_{1} \leq 50 \%$ at $60 \mathrm{~min}$. However, after recruitment of the initial 19 subjects it was apparent that the main determinant of this outcome was the baseline $\mathrm{PtCO}_{2}$, rather than whether an increase in $\mathrm{PtCO}_{2}$ had actually occurred. Specifically, of the $3 / 19$ subjects who met the primary end point, two had a decrease in $\mathrm{PtCO}_{2}$ (from 46 to $39 \mathrm{~mm} \mathrm{Hg}$ and from 45 to $44 \mathrm{~mm} \mathrm{Hg}$ ) and the other had a minimal increase (from 39 to $40 \mathrm{~mm} \mathrm{Hg}$ ). For this reason, after the initial 19 subjects were studied, the primary outcome was changed to the proportion of patients with a $\mathrm{PtCO}_{2}$ rise of $\geq 4 \mathrm{~mm} \mathrm{Hg}$ at $60 \mathrm{~min}$, and the proportion of patients with a $\mathrm{PtCO}_{2}$ rise of $\geq 4 \mathrm{~mm} \mathrm{Hg}$ and a $\mathrm{PtCO}_{2} \geq 38 \mathrm{~mm} \mathrm{Hg}$ at $60 \mathrm{~min}$ was included as a secondary outcome variable. Other secondary outcome variables included the mean change in $\mathrm{PtCO}_{2}$ from baseline, changes in respiratory rate, heart rate and $\mathrm{FEV}_{1}$, and the need for hospital admission at the end of the ED treatment period. The proportion of patients with a $\mathrm{PtCO}_{2}$ rise of $\geq 8 \mathrm{~mm} \mathrm{Hg}$ was added as a posthoc outcome variable.

The rate of change of $\mathrm{PtCO}_{2}$ was determined using a mixed linear model with random intercept and slope terms. ${ }^{27}$ In the mixed linear model the fixed effects were the randomised treatment as a dichotomous variable, time as a continuous covariate, and a treatment $\times$ time interaction term. A random slope and intercept term with the individual participants as subjects and an unstructured covariance specified for the intercept and slope accounted for the correlation of repeated measurements on the same participants. Continuous outcome variables were analysed as change from baseline using independent sample t tests, or for achieved oxygen saturation for which normality assumptions were not met, by a Mann-Whitney test. Logistic regression was used to model the risk of admission, expressed as an OR, both unadjusted for other variables and adjusted for baseline $\mathrm{FEV}_{1}$, baseline oxygen saturation and baseline $\mathrm{PtCO}_{2}$. Analysis was by intention to treat. SAS version 9.1 and Minitab version 14 were used.

\section{Sample size calculation}

Based on previous research ${ }^{19}$ we calculated that to detect a difference in the proportion of patients with the primary outcome variable of $20 \%$ in the high concentration oxygen group and $5 \%$ in the titrated group, with power of $80 \%$ at a type 1 error rate of $5 \%, 75$ subjects were required in each group.

\section{RESULTS}

Eligible patients were recruited from July 2007 to December 2009. A total of 106 patients were randomised, 53 to the high concentration group and 53 to the titrated group. Three patients were withdrawn from the high concentration oxygen group, two due to protocol violations in which the patients met an exclusion criterion after randomisation (one patient with COPD and one with obesity hypoventilation syndrome), and in one patient a reliable $\mathrm{PtCO}_{2}$ signal could not be obtained. As a result there were data from 50 patients in the high concentration group and 53 in the titrated group for final analysis. Figure 1 shows the flow of the patients through the study. The two oxygen treatment groups were well matched with respect to age, sex and respiratory rate (table 1). The mean baseline $\mathrm{FEV}_{1}$ in the high concentration oxygen and titrated oxygen groups was 1.15 and 1.29 litres, respectively.

$\mathrm{PtCO}_{2}$ levels at baseline ranged from 14 to $50 \mathrm{~mm} \mathrm{Hg}$ (figure 2). The majority of patients were hypocapnic at baseline, with 68/103 (66\%) having a $\mathrm{PtcO}_{2}<38 \mathrm{~mm} \mathrm{Hg}$. There were 


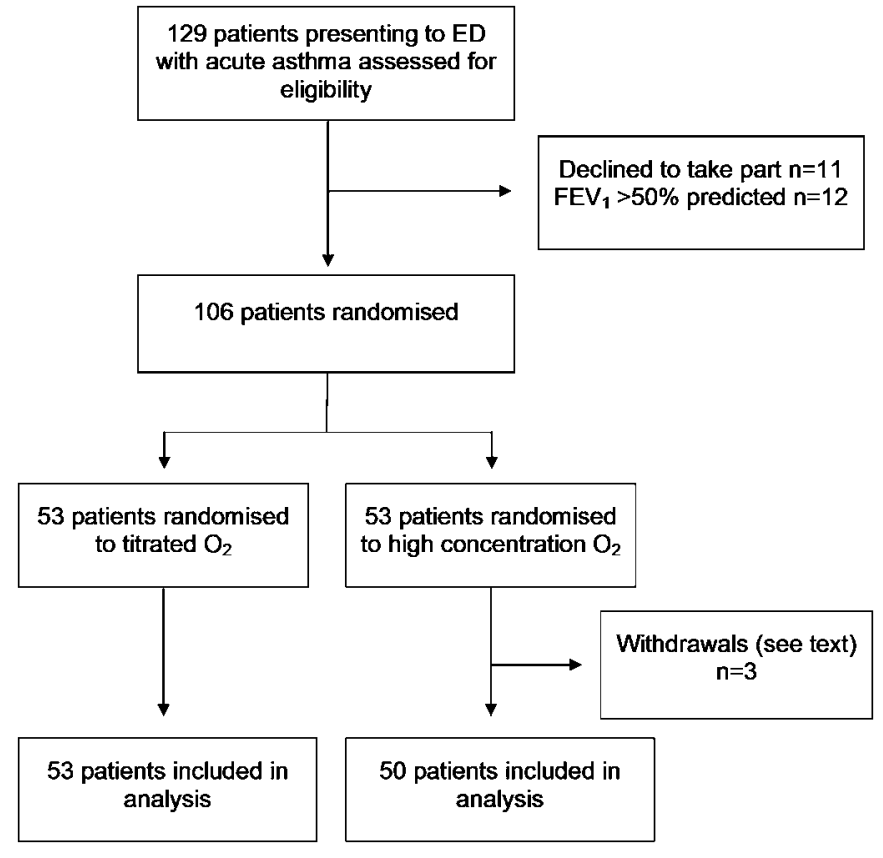

Figure 1 Flow of patients through the study. ED, Emergency Department; $\mathrm{FEV}_{1}$, forced expiratory volume in $1 \mathrm{~s}$.

eight patients with an oxygen saturation $<93 \%$ at baseline while breathing room air. In the titrated oxygen group, 48/53 $(90 \%)$ patients did not require oxygen therapy throughout the $60 \mathrm{~min}$ treatment period, four patients required $1-3 \mathrm{l} / \mathrm{min}$ and one required $>3 \mathrm{l} / \mathrm{min}$. In the high concentration oxygen group the oxygen saturation at $60 \mathrm{~min}$ was $\geq 99 \%$ in $39 / 50(78 \%)$ patients and was $\geq 95 \%$ in the remaining 11 patients.

The $\mathrm{PtCO}_{2}$ levels at $60 \mathrm{~min}$ ranged from 18 to $52 \mathrm{~mm} \mathrm{Hg}$ (figure 2). One patient who received high concentration oxygen was withdrawn after $11 \mathrm{~min}$ due to safety concerns, following an increase in the $\mathrm{PtCO}_{2}$ from 41 to $52 \mathrm{~mm} \mathrm{Hg}$. For the categorical outcome variables, the $\mathrm{PtCO}_{2}$ value at 11 min was used as the final measurement in this patient. A total of 10 patients had a final $\mathrm{PtCO}_{2} \geq 45 \mathrm{~mm} \mathrm{Hg}$. All 10 patients were in the high concentration oxygen group, and in five patients there was an increase in $\mathrm{PtCO}_{2} \geq 10 \mathrm{~mm} \mathrm{Hg}$.

The proportion of patients with an increase in $\mathrm{PtCO}_{2}$ of $\geq 4 \mathrm{~mm} \mathrm{Hg}$ at $60 \mathrm{~min}$ was significantly greater in the high concentration group, compared with the titrated oxygen group, with an RR of 2.3 (95\% CI 1.2 to 4.4 ; $\mathrm{p}=0.006$ ) (table 2).

The proportion of patients with a rise in $\mathrm{PtCO}_{2} \geq 8 \mathrm{~mm} \mathrm{Hg}$ was significantly greater in the high concentration group, with

Table 1 Baseline characteristics of patients

\begin{tabular}{lccc}
\hline & $\begin{array}{l}\text { High concentration } \mathbf{0}_{2} \\
(\mathbf{n = 5 0 )}\end{array}$ & $\begin{array}{l}\text { Titrated } \mathbf{0}_{\mathbf{2}} \\
(\mathbf{n = 5 3})\end{array}$ & $\begin{array}{l}\text { All } \\
(\mathbf{n = 1 0 3 )}\end{array}$ \\
\hline Sex, male N (\%) & $27(54)$ & $18(34)$ & $45(43.7)$ \\
Age, years & $35.0(14.4)$ & $32.6(11.1)$ & $33.8(12.8)$ \\
Respiratory rate, breaths/min & $23.4(6.6)$ & $22.7(5.7)$ & $23.0(6.1)$ \\
Heart rate, beats/min & $97.7(23.4)$ & $100.7(18.8)$ & $99.2(21.1)$ \\
$\mathrm{Sp}_{2}, \%$ & $95.1(3.2)$ & $96.4(2.7)$ & $95.8(3.0)$ \\
$\mathrm{Ptc}_{2}, \mathrm{~mm} \mathrm{Hg}$ & $36(7.1)$ & $34.1(5.7)$ & $35(6.4)$ \\
$\mathrm{Ptco}_{2} \geq 38 \mathrm{~mm} \mathrm{Hg}$ & $20(40.0)$ & $15(28.3)$ & $35(34.0)$ \\
$\mathrm{FEV}_{1}, \mathrm{l} / \mathrm{min}$ & $1.15(0.43)$ & $1.29(0.44)$ & $1.22(0.44)$ \\
$\mathrm{FEV}_{1} \%$ predicted & $32.1(9.9)$ & $36.9(9.7)$ & $34.6(10.1)$ \\
\hline
\end{tabular}

Values for age, respiratory rate, heart rate, $\mathrm{SpO}_{2}, \mathrm{Ptco}_{2}, \mathrm{FEV}_{1}$ and $\mathrm{FEV}_{1} \%$ predicted are mean (SD). Values for sex and $\mathrm{Ptc}_{2} \geq 38 \mathrm{~mm} \mathrm{Hg}$ are number of patients (percentage). $\mathrm{FEV}_{1}$, forced expiratory volume in $1 \mathrm{~s}$; $\mathrm{Ptco}_{2}$, transcutaneous partial pressure of carbon dioxide.

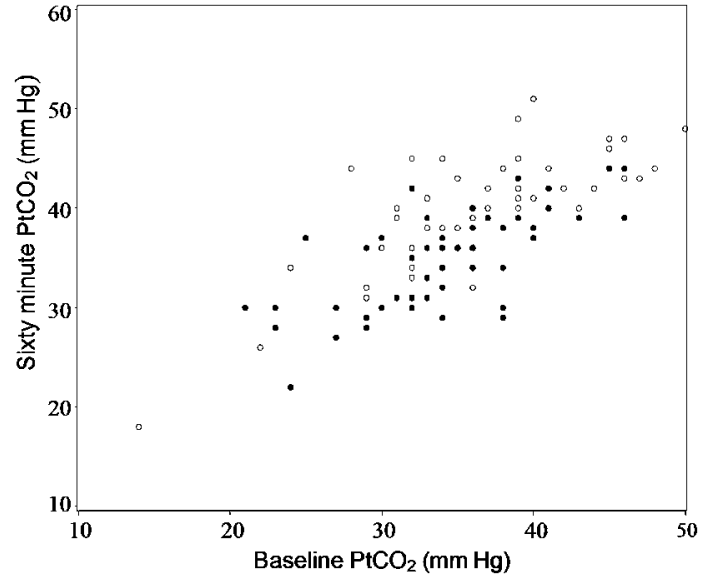

Figure 2 The transcutaneous partial pressure of carbon dioxide $\left(\mathrm{PtcO}_{2}\right)$ levels at baseline and after $60 \mathrm{~min}$ in the high concentration (open circles) and titrated (filled circles) oxygen groups. The patient who received high concentration oxygen and was withdrawn after 11 min due to safety concerns, following an increase in the $\mathrm{Ptco}_{2}$ from 41 to $52 \mathrm{~mm} \mathrm{Hg}$ is not presented in the figure.

an RR of 3.9 (95\% CI 1.2 to 13.1, $\mathrm{p}=0.016)$. The proportion of patients with a $\mathrm{PtCO}_{2}>38 \mathrm{~mm} \mathrm{Hg}$ and an $\mathrm{FEV}_{1}$ percentage predicted $\leq 50 \%$ after 60 min was $20 / 49$ (40.8\%) in the high concentration group and $6 / 53(11.3 \%)$ in the titrated group, RR $3.6(95 \%$ CI 1.6 to $8.2 ; \mathrm{p}<0.001)$.

The mean change in $\mathrm{PtCO}_{2}$ from baseline was significantly greater in the high concentration group, with a mean difference between the groups at $60 \mathrm{~min}$ of $2.6 \mathrm{~mm} \mathrm{Hg}$ (95\% CI 0.9 to 4.3; $\mathrm{p}<0.003$ ) (table 3). The proportion of patients with a rise in $\mathrm{PtCO}_{2} \geq 4 \mathrm{~mm} \mathrm{Hg}$ was greater in the high concentration group at the 20 and 40 min time points (table 3 ). The rate of increase in the high concentration group was 0.054 ( $95 \%$ CI 0.035 to 0.074 ) $\mathrm{mm} \mathrm{Hg} / \mathrm{min}$ and in the titrated group it was $0.012(95 \% \mathrm{CI}$ -0.0065 to 0.031$) \mathrm{mm} \mathrm{Hg} / \mathrm{min}$. The difference in the rate of change was $0.042 \mathrm{~mm} \mathrm{Hg} / \mathrm{min}$ ( $95 \%$ CI 0.069 to $0.15, \mathrm{p}=0.003$ ).

There were $26 / 50$ (52\%) of the high concentration group admitted to hospital compared with $17 / 53$ (32\%) in the titrated group, OR 2.29 (95\% CI 1.03 to $5.10, \mathrm{p}=0.042$ ). After adjusting for baseline $\mathrm{FEV}_{1}$, baseline oxygen saturation and baseline $\mathrm{PtCO}_{2}$, this OR was 1.7 (95\% CI 0.68 to $4.26, p=0.257$ ) (table 4). In the adjusted analysis, a higher baseline $\mathrm{FEV}_{1}$ and oxygen saturation were associated with a reduced risk of admission. There was no difference between the treatment groups in the mean change of respiratory rate, pulse rate or $\mathrm{FEV}_{1}$ over $60 \mathrm{~min}$ (see online supplement Table S2).

\section{DISCUSSION}

This randomised controlled trial has shown that high concentration oxygen therapy results in a significant increase in $\mathrm{PtCO}_{2}$

Table 2 The proportion of patients with a predetermined rise in the transcutaneous partial pressure of carbon dioxide $\left(\mathrm{Ptco}_{2}\right)$ from baseline at $60 \mathrm{~min}$

\begin{tabular}{lllll}
\hline & $\begin{array}{l}\text { High concentration } \\
\mathbf{0}_{\mathbf{2}} \mathbf{n}(\%)\end{array}$ & $\begin{array}{l}\text { Titrated } \mathbf{0}_{\mathbf{2}} \\
\mathbf{n}(\%)\end{array}$ & $\begin{array}{l}\mathbf{R R} \\
\mathbf{( 9 5 \%} \mathbf{~ C l )}\end{array}$ & p Value \\
\hline $\begin{array}{l}\text { Change in } \mathrm{Ptco}_{2} \\
\geq 4 \mathrm{~mm} \mathrm{Hg}\end{array}$ & $22(44 \%)$ & $10(19 \%)$ & $2.3(1.2$ to 4.4$)$ & 0.006 \\
$\begin{array}{l}\text { Change in Ptco } \\
\geq 4 \mathrm{~mm} \mathrm{Hg} \mathrm{and} \mathrm{Ptco} 2\end{array}$ & $17(34 \%)$ & $4(8 \%)$ & $4.5(1.6$ to 12.5$)$ & 0.001 \\
$\geq 38 \mathrm{~mm} \mathrm{Hg}$ & & & & \\
$\begin{array}{l}\text { Change in Ptco } \\
\geq 8 \mathrm{~mm} \mathrm{Hg}\end{array}$ & $11(22 \%)$ & $3(6 \%)$ & $3.9(1.2$ to 13.1$)$ & 0.016 \\
\hline
\end{tabular}


Table 3 Time course of changes in the transcutaneous partial pressure of carbon dioxide $\left(\mathrm{PtCO}_{2}\right)$ in the treatment groups

(1) The mean change in $\mathrm{Ptco}_{2}(\mathrm{~mm} \mathrm{Hg})$

\begin{tabular}{|c|c|c|c|c|}
\hline Time & $\begin{array}{l}\text { High concentration } \mathrm{O}_{2} \\
\text { mean (SD) }\end{array}$ & $\begin{array}{l}\text { Titrated } \mathrm{O}_{2} \\
\text { mean (SD) }\end{array}$ & $\begin{array}{l}\text { Difference } \\
(95 \% \mathrm{CI})\end{array}$ & p Value \\
\hline $20 \mathrm{~min}$ & $2.8(4.1)$ & $0.3(3.6)$ & $2.5(1.0$ to 4.0$)$ & 0.001 \\
\hline $40 \mathrm{~min}$ & $3.0(4.7)$ & $0.4(3.8)$ & $2.6(0.9$ to 4.3$)$ & 0.002 \\
\hline $60 \mathrm{~min}$ & $3.4(4.5)$ & $0.8(4.1)$ & $2.6(0.9$ to 4.3$)$ & 0.003 \\
\hline \multicolumn{5}{|c|}{ (2) The proportion of patients with a rise in $\mathrm{Ptco}_{2} \geq 4 \mathrm{~mm} \mathrm{Hg}$} \\
\hline Time & $\begin{array}{l}\text { High concentration } \mathrm{O}_{2} \\
\mathrm{~N}(\%)\end{array}$ & $\begin{array}{l}\text { Titrated } \mathbf{O}_{2} \\
\mathbf{N}(\%)\end{array}$ & RR (95\% CI) & p Value \\
\hline $20 \mathrm{~min}$ & $15(30 \%)$ & 7 (13\%) & $2.3(1.0$ to 5.1$)$ & 0.038 \\
\hline $40 \mathrm{~min}$ & $21(42 \%)$ & $8(15 \%)$ & 2.8 (1.4 to 5.7$)$ & 0.002 \\
\hline $60 \mathrm{~min}$ & $22(44 \%)$ & $10(19 \%)$ & 2.3 (1.2 to 4.4$)$ & 0.006 \\
\hline
\end{tabular}

compared with titrated oxygen when administered to patients presenting to the ED with severe exacerbations of asthma. We propose that the results are of physiological and clinical significance, as indicated by the two- to fourfold RR of an increase in $\mathrm{PtCO}_{2}$ of at least 4 or $8 \mathrm{~mm} \mathrm{Hg}$, respectively, in the group receiving high concentration oxygen. Furthermore, all 10 patients who developed hypercapnia with a final $\mathrm{PtCO}_{2}$ $\geq 45 \mathrm{~mm} \mathrm{Hg}$ had received high concentration oxygen therapy. This observation suggests that the administration of high concentration oxygen in the ED setting is a determinant of the development of respiratory failure, a recognised marker of near fatal asthma. ${ }^{22}$ After adjustment for baseline predictors of severity, high flow oxygen was not statistically significant as a predictor of hospital admission, although the point estimate was consistent with an increased risk.

The results of the current study extend those of the only previous randomised controlled trial of high concentration oxygen in acute severe asthma. ${ }^{19}$ In this previous study, 74 patients were given $100 \%$ or $28 \%$ oxygen for 20 min on arrival to the ED prior to receiving any asthma treatment. The difference in the mean rise in $\mathrm{PaCO}_{2}$ between the groups was $2.7 \mathrm{~mm} \mathrm{Hg}$, similar to the $2.6 \mathrm{~mm} \mathrm{Hg}$ noted in the current study. However, the duration of oxygen therapy was only $20 \mathrm{~min}$ and no concurrent asthma treatment was administered, limiting the generalisability of their study findings. Also, the administration of $28 \%$ oxygen rather than a titrated oxygen regime differed from the therapeutic approach currently recommended in guidelines. ${ }^{22-24}$ Our study and others ${ }^{8}$ have shown that most adult patients presenting to the ED with severe exacerbations of asthma do not have hypoxaemia, and, as a result, do not require initial oxygen therapy.

There are a number of methodological issues relevant to the interpretation of the study findings. The first is that we used a transcutaneous $\mathrm{CO}_{2}$ monitor to measure $\mathrm{PaCO}_{2}$ rather than the 'gold standard' arterial blood gas (ABG) test. This method was

Table 4 Risk of hospital admission

\begin{tabular}{lll}
\hline & OR (95\% Cl) & p Value \\
\hline $\begin{array}{l}\text { (1) Unadjusted analysis } \\
\text { High concentration oxygen* }\end{array}$ & $2.29(1.03$ to 5.10$)$ & 0.042 \\
$\begin{array}{l}\text { (2) Adjusted analysis } \\
\quad \text { High concentration oxygen }\end{array}$ & $1.70(0.68$ to 4.26$)$ & 0.257 \\
$\quad$ Baseline oxygen saturation (per \%) & $0.80(0.66$ to 0.98$)$ & 0.028 \\
$\quad$ Baseline Ptco ${ }_{2}$ (per mm Hg) & $1.04(0.96$ to 1.12$)$ & 0.370 \\
Baseline $\mathrm{FEV}_{1}$ (per litre) & $0.31(0.10$ to 0.94$)$ & 0.039 \\
\hline
\end{tabular}

*High concentration oxygen versus titrated oxygen.

$\mathrm{FEV}_{1}$, forced expiratory volume in $1 \mathrm{~s} ; \mathrm{Ptco}_{2}$, transcutaneous partial pressure of carbon dioxide. chosen as it allowed continuous $\mathrm{PtCO}_{2}$ monitoring without the discomfort of multiple $\mathrm{ABG}$ sampling or the risk of hand ischaemia associated with indwelling radial artery cannulae. The accuracy of transcutaneous $\mathrm{CO}_{2}$ monitoring has been demonstrated in a variety of settings including healthy subjects, ${ }^{28}$ AECOPD, ${ }^{29}$ sleep disorders, ${ }^{30}$ critical illness ${ }^{31}$ and in a mixed group of patients presenting to an ED. ${ }^{32}$ We also assessed the accuracy of our device in a subset of patients who had simultaneous $\mathrm{ABG}$ and $\mathrm{PtCO}_{2}$ recordings. ${ }^{33}$ It accurately measured $\mathrm{PaCO}_{2}$ without significant bias and with clinically acceptable limits of agreement when compared with the ABG measurement, thus validating our methodology.

By necessity the study was unblinded, as there was a clinical requirement for the investigator to have knowledge of the oxygen saturations in order to titrate the oxygen therapy in the 'control' treatment group. The objective display of $\mathrm{PtCO}_{2}$ on the monitor avoided subjective assessment of the primary outcome variable. In the titrated oxygen group, the target oxygen saturation was $93-95 \%$ to ensure both that hypoxaemia was relieved and that hyperoxaemia was avoided.

Our prespecified analysis plan was to use the proportion of patients with a $\mathrm{PtCO}_{2}>38 \mathrm{~mm} \mathrm{Hg}$ and $\mathrm{FEV}_{1} \leq 50 \%$ at $60 \mathrm{~min}$ as the primary outcome variable. However, in the early phase of recruitment it was apparent that the prespecified primary outcome variable was primarily determined by the presenting $\mathrm{PtCO}_{2}$ rather than by a physiological increase in $\mathrm{PtCO}_{2}$. After a review of the records of the first 19 patients (representing $17 \%$ of 106 patients contributing to the main outcome analysis) we registered a change in the primary outcome variable to the proportion of patients with a $\mathrm{PtCO}_{2}$ rise of $\geq 4 \mathrm{~mm} \mathrm{Hg}$. We acknowledge that changing the primary outcome variable after the start of the study raises the possibility of creating a biased assessment of the outcome of the trial. However, no formal interim statistical analysis, of either the prespecified outcome variable or the new main outcome variable, was carried out prior to this decision and, although the study itself was not masked as to treatment allocation, the decision was made without reference to the randomised allocation of the patients. In the event, for the prespecified main outcome variable, $\mathrm{PtCO}_{2}$ $>38 \mathrm{~mm} \mathrm{Hg}$ and an $\mathrm{FEV}_{1}$ percentage predicted $\leq 50 \%$ after $60 \mathrm{~min}$, the 3.6-fold increased risk associated with high concentration oxygen therapy was similar to the 2.3and 3.9-fold increased risk observed with a $\mathrm{PtCO}_{2}$ rise of $\geq 4$ and $\geq 8 \mathrm{~mm} \mathrm{Hg}$, respectively.

We had intended to recruit 150 patients, based on the power calculation derived from the previous randomised controlled trial of oxygen therapy in asthma. ${ }^{19}$ Due to difficulties with recruitment, we extended the study sites to include Hutt Hospital, and the planned 2 year study period by 6 months With these measures we enrolled 106 patients, which provided sufficient statistical power to determine clinically relevant differences between the treatment groups. Patients with a diagnosis of COPD were excluded due to the known effect of high concentration oxygen in exacerbations of this disorder. ${ }^{1-7}$ It is probable that greater increases in $\mathrm{PtCO}_{2}$ may occur in an unselected population of patients with acute asthma, which is more likely to include those with concomitant undiagnosed COPD or other disorders associated with chronic respiratory failure.

Although an attempt was made to include potential patients with severe or life-threatening asthma, patients who were moribund, unable to speak, unable to perform spirometry or so distressed that they could not consent were not enrolled. Consequently, those with the most severe airflow obstruction, and hence the highest risk of hypercapnia at presentation, were 
not able to be studied. In this regard it is relevant that with progressively more severe hypercapnia, smaller falls in alveolar ventilation are required to produce a given further rise in $\mathrm{PaCO}_{2}{ }^{34}$

The increase in $\mathrm{PaCO}_{2}$ with high concentration oxygen demonstrated in this study is also likely to be an underestimate of the magnitude of the effect that may be seen in standard clinical practice, in which oxygen therapy may be administered for a longer period. The $\mathrm{PtCO}_{2}$ progressively increased in the high concentration group throughout the 60 min study period, suggesting that some patients may have had further increases in $\mathrm{PtCO}_{2}$ had the high concentration oxygen regime continued.

The main mechanism for the elevation in $\mathrm{PtCO}_{2}$ demonstrated in this study is likely to be worsening ventilation-perfusion mismatching as a result of the release of hypoxic pulmonary vasoconstriction and a consequent increase in physiological dead space. This has been demonstrated in studies of the effects of oxygen therapy in both acute severe and chronic asthma, ${ }^{10-15}$ and is one of the main mechanisms which causes oxygeninduced $\mathrm{CO}_{2}$ retention in AECOPD. ${ }^{3-7}$ As a result, one of the important clinical implications of our study is that high concentration oxygen therapy may have the potential to cause an increase in $\mathrm{PaCO}_{2}$ across a range of respiratory conditions with abnormal gas exchange due to ventilation-perfusion inequality. In support of this interpretation, this physiological response to high concentration oxygen therapy has now been reported in stable COPD, ${ }^{5}$ AECOPD, ${ }^{1} 246$ asthma, ${ }^{10-12} 181921$ obesity hypoventilation syndrome $e^{35} 36$ and diffuse pulmonary fibrosis or infiltration. ${ }^{37}$ This response contrasts with that observed in normal subjects in whom high concentration oxygen therapy leads to a small decrease in $\mathrm{PaCO}_{2} .{ }^{38} 39$ The observation that there was no difference in the change in $\mathrm{FEV}_{1}$ between the two regimes suggests that the increase in $\mathrm{PtCO}_{2}$ with high concentration oxygen therapy was not due to a bronchoconstrictor effect related to the low humidity of the delivered oxygen.

We conclude that high concentration oxygen increases the risk of hypercapnia in patients with severe exacerbations of asthma. Our findings also suggest that the potential increase in $\mathrm{PaCO}_{2}$ with high concentration oxygen therapy is not limited to asthma and COPD, but may also occur in other respiratory disorders with abnormal gas exchange. Consistent with recent guidelines, ${ }^{22-24}$ we recommend a titrated oxygen regime in patients with severe exacerbations of asthma, in which oxygen is administered only to those with evidence of arterial hypoxaemia, in a dose that relieves the hypoxaemia without causing hyperoxaemia, thereby obtaining the benefits while reducing the potential for harm.

Funding Funding was received from the Health Research Council of New Zealand, the Wellington Hospitals and Health Foundation, the Asthma and Respiratory Foundation of New Zealand and the Royal Australasian College of Physicians.

Competing interests None.

Ethics approval This study was conducted with the approval of the Central Regional Ethics Committee.

Provenance and peer review Not commissioned; externally peer reviewed.

\section{REFERENCES}

1. Westlake EK, Simpson T, Kaye M. Carbon dioxide narcosis in emphysema. $0 \mathrm{~J}$ Med 1955:94:155-73.

2. Murphy R, Driscoll P, O'Driscoll R. Emergency oxygen therapy for the COPD patient. Emerg Med J 2001;18:332-9.

3. Aubier M, Murciano D, Fournier M, et al. Central respiratory drive in acute respiratory failure of patients with chronic obstructive pulmonary disease. Am Rev Respir Dis 1980;122:191-9.
4. Aubier M, Murciano D, Milic-Emili $\mathrm{J}$, et al. Effects of the administration of $\mathrm{O}_{2}$ on ventilation and blood gases in patients with chronic obstructive pulmonary disease during acute respiratory failure. Am Rev Respir Dis 1980;122:747-54.

5. Dick C, Liu Z, Sassoon C, et al. $\mathrm{O}_{2}$-induced change in ventilation and ventilatory drive in COPD. Am J Respir Crit Care Med 1997;155:609-14.

6. Robinson TD, Freiberg DB, Regnis JA, et al. The role of hypoventilation and ventilation-perfusion redistribution in oxygen-induced hypercapnia during acute exacerbations of chronic obstructive pulmonary disease. Am J Respir Crit Care Med 2000;161:1524-9.

7. Sassoon CS, Hassell KT, Mahutte CK. Hyperoxic-induced hypercapnia in stable chronic obstructive pulmonary disease. Am Rev Respir Dis 1987;135:907-11.

8. McFadden ER Jr, Lyons HA. Arterial-blood gas tension in asthma. N Engl J Med 1968;278:1027-32.

9. Ferrer A, Roca J, Wagner PD, et al. Airway obstruction and ventilation-perfusion relationships in acute severe asthma. Am Rev Respir Dis 1993;147:579-84.

10. Rodriguez-Roisin R, Ballester E, Roca J, et al. Mechanisms of hypoxemia in patients with status asthmaticus requiring mechanical ventilation. Am Rev Respir Dis 1989;139:732-9.

11. Ballester $\mathbf{E}$, Reyes A, Roca J, et al. Ventilation-perfusion mismatching in acute severe asthma: effects of salbutamol and 100\% oxygen. Thorax 1989:44:258-67.

12. Field GB. The effects of posture, oxygen, isoproterenol and atropine on ventilation-perfusion relationships in the lung in asthma. Clin Sci 1967;32:279-88.

13. Ballester $\mathbf{E}$, Roca J, Ramis $\mathrm{L}$, et al. Pulmonary gas exchange in severe chronic asthma. Response to 100\% oxygen and salbutamol. Am Rev Respir Dis 1990;141:558-62.

14. Corte $\mathbf{P}$, Young $\mathbf{I H}$. Ventilation-perfusion relationships in symptomatic asthma. Response to oxygen and clemastine. Chest 1985;88:167-75.

15. Valabhji P. Gas exchange in the acute and asymptomatic phases of asthma breathing air and oxygen. Clin Sci 1968:34:431-40.

16. Beale HD, Schiller IW, Halperin MH, et al. Delirium and coma precipitated by oxygen in bronchial asthma complicated by respiratory acidosis. N Engl J Med 1951;244:710-14.

17. Simpson H, Forfar JO, Grubb DJ. Arterial blood gas tensions and pH in acute asthma in childhood. Br Med J 1968;3:460-4.

18. Chien JW, Ciufo R, Novak $R$, et al. Uncontrolled oxygen administration and respiratory failure in acute asthma. Chest 2000;117:728-33.

19. Rodrigo GJ, Rodriquez Verde M, Peregalli V, et al. Effects of short-term $28 \%$ and $100 \%$ oxygen on $\mathrm{PaCO}_{2}$ and peak expiratory flow rate in acute asthma: a randomized trial. Chest 2003;124:1312-17.

20. Tai E, Read J. Blood-gas tensions in bronchial asthma. Lancet 1967;1:644-6.

21. Rudolf M, Turner JA, Harrison BD, et al. Changes in arterial blood gases during and after a period of oxygen breathing in patients with chronic hypercapnic respiratory failure and in patients with asthma. Clin Sci 1979;57:389-96.

22. Scottish Intercollegiate Guidelines Network and British Thoracic Society. British Guideline on the Management of Asthma: A National Clinical Guideline. 2009. http://www.sign.ac.uk/pdf/sign101.pdf.

23. Bateman ED, Hurd SS, Barnes PJ, et al. Global strategy for asthma management and prevention: GINA executive summary. Eur Respir J 2008;31:143-78.

24. O'Driscoll BR, Howard LS, Davison AG; On behalf of the British Thoracic Society. BTS Guideline for emergency oxygen use in adult patients. Thorax 2008;63(Suppl vi):vi1-68.

25. Milross J, Young IH, Donnelly P. The oxygen delivery characteristics of the Hudson Oxy-one face mask. Anaesth Intensive Care 1989:17:180-4.

26. Garcia JA, Gardner D, Vines D, et al. The oxygen concentrations delivered by different oxygen therapy systems. Chest 2005;128:389S-90S

27. Brown H, Prescott R. Applied Mixed Linear Models in Medicine. 2nd edn. Chichester: John Wiley \& Sons, 2006

28. Fuke S, Miyamoto $\mathrm{K}$, Ohira $\mathrm{H}$, et al. Evaluation of transcutaneous $\mathrm{CO}_{2}$ responses following acute changes in $\mathrm{PaCO}_{2}$ in healthy subjects. Respirology 2009;14:436-42.

29. Cox M, Kemp R, Anwar $\mathrm{S}$, et al. Non-invasive monitoring of $\mathrm{CO}_{2}$ levels in patients using NIV for AECOPD. Thorax 2006:61:363-4.

30. Senn 0, Clarenbach CF, Kaplan V, et al. Monitoring carbon dioxide tension and arterial oxygen saturation by a single earlobe sensor in patients with critical illness or sleep apnea. Chest 2005;128:1291-6.

31. Rodriguez P, Lellouche F, Aboab J, et al. Transcutaneous arterial carbon dioxide pressure monitoring in critically ill adult patients. Intensive Care Med 2006;32:309-12

32. McVicar J, Eager R. Validation study of a transcutaneous carbon dioxide monitor in patients in the emergency department. Emerg Med J 2009;26:344-6.

33. Perrin K, Wijesinghe $\mathrm{M}$, Weatherall $\mathrm{M}$, et al. Assessing $\mathrm{PaCO}_{2}$ in acute respiratory disease: accuracy of a transcutaneous carbon dioxide device. Intern Med $\mathrm{J}$ 2011;:41:585-646.

34. Stradling JR. Hyercapnia during oxygen therapy in airways obstruction a reappraisal. Thorax 1986;41:897-902.

35. Barrera $\mathbf{F}$, Hillyer $P$, Ascanio $G$, et al. The distribution of ventilation, diffusion, and blood flow in obese patients with normal and abnormal blood gases. Am Rev Respir Dis 1973;108:819-30.

36. Wijesinghe $\mathbf{M}$, Williams $\mathbf{M}$, Perrin $\mathrm{K}$, et al. The effect of supplemental oxygen on hypercapnia in subjects with obesity-associated hypoventilation: a randomized cross-over clinical study. Chest 2011;139:1018-24.

37. Said SI, Banerjee CM. Venous admixture to the pulmonary circulation in human subjects breathing 100 per cent oxygen. J Clin Invest 1963:42:507-15.

38. Becker H, Polo 0, McNamara S, et al. Effect of different levels of hyperoxia on breathing in healthy subjects. J Appl Physiol 1996:81:1683-90.

39. Iscoe S, Fisher JA. Hyperoxia-induced hypocapnia: an underappreciated risk. Chest 2005; 128:430-3 